\title{
Impact of Roadside Advertising Structures on Traffic Safety
}

\author{
Suada Dacić, Amel Kosovac, Adnan Omerhodžić \\ Faculty of Traffic and Communications, University of Sarajevo, Zmaja od Bosne 8, \\ Sarajevo, Bosnia and Herzegovina
}

\begin{abstract}
The focus of research presented in this paper is quantification of the relationship between the traffic safety and roadside advertising structures along a selected road in urban environment. In order to determine correlation, statistical analysis of traffic safety indicators was performed. Then identificcation of characteristics of advertising structures and analysis was done by using multi-criteria evaluation in order to determine their impact on driver distraction. Determination of driver distraction was performed by testing the drivers in real traffic conditions, using specialized measuring equipment. The indicators derived from the research were then analyzed using the methods of regression analysis, and safety.
\end{abstract}

Keywords - Traffic safety, driver distraction, advertising structures.

\section{Introduction}

The main focus of any road safety system is traffic accidents and their negative consequences including number of human deaths and injuries, and material damage. Traffic accidents are complex events which demand special treatment and analysis.

DOI: 10.18421/TEM111-23

https://doi.org/10.18421/TEM111-23

Corresponding author: Adnan Omerhodžić,

Faculty of Traffic and Communications, University of Sarajevo, Zmaja od Bosne 8, Sarajevo, Bosnia and Herzegovina.

Email: adnan.omerhodzic@fsk.unsa.ba

Received: 17 October 2021.

Revised: 18 December 2021.

Accepted: 25 December 2021.

Published: 28 February 2022.

(cc) BY-NC-ND_C 2022 Suada Dacić, Amel Kosovac \& Adnan Omerhodžić; published by UIKTEN. This work is licensed under the Creative Commons AttributionNonCommercial-NoDerivs 4.0 License.

The article is published with Open Access at https://www.temjournal.com/
The complexity of traffic accidents is particularly challenging in urban areas, because urban areas generate an increase in mobility. Urban environments are characterized by specific traffic flows of different types and different participants. One of the main causes of reduced safety in road traffic in urban areas is the distraction of drivers or a temporary lack of attention to safe driving [1].

Identifying the causes of traffic accidents is a key goal of traffic safety experts. Efficient and precise identification of the causes in dangerous places on the road network is especially important. [2] The issue of identifying causes of traffic accidents is exceptionally challenging in urban areas due to the complexity of the elements of the immediate environment along the roads which altogether cause driver distractions and can lead to traffic accidents. Adequate treatment of the environment as one of the basic factors of traffic safety implies a special focus on advertising structures that are almost always positioned in the immediate proximity of the road.

Advertising structures, as a means of marketing, aim to reach as many potential users or consumers of the advertised product or service as possible. Thus, due to high traffic flows and increased concentration of people and vehicles the network of roads in urban areas is becoming one of the most attractive areas for advertising. The success of advertising using advertising structures depends on several key factors: visualization, creativity, and innovation.

Requirements to achieve successful advertising using particular structures by securing the above characteristics in the traffic environment are substantially in conflict with the requirements of achieving greater safety in traffic. According to the research [3], driver distraction and inattention in their various forms was a factor in $20-30 \%$ of the analyzed traffic accidents. Driver distraction research is particularly focused on investigating the impact of advertising structures on driver behavior and traffic safety [4].

From the aspect of traffic safety, advertising structures represent one of the most important groups of objects/structures in the traffic environment that have impact on driver distraction [5]. Distraction is classified as an extremely negative phenomenon and a significant influencing factor in the occurrence of incidental situations and traffic accidents. Distraction 
of drivers in traffic implies distraction and loss of focus on driving caused by an object or event. Distractions of traffic participants can be divided into: visual, cognitive, physical, and auditory [1]. According to the above classification, advertising structures cause visual distraction in all three forms:

- Limited field of view due to the construction of an advertising structure that prevents visibility and/or spotting other traffic participants (mostly spotting other vehicles or pedestrians in the intersection area);

- Distraction from the traffic situation and driving, as a result of directing the gaze into the advertising structure (keeping the gaze because of an interesting content);

- Loss of visual attention resulting in loss of the ability to detect hazards (diverting gaze from the road as a result of thinking about textual and/or visual content previously observed on an advertising structure).

Advertising structures, which are quite similar in their characteristics to the elements of vertical traffic signs/signals, are not adequately regulated in the legislation that should effectively provide increasing traffic safety. On the other hand, the elements of vertical traffic signs/signals are regulated by strict standards and regulations that, inter alia, regulate: Specific position, sign size, retroreflection, color, construction, shape, distance from the road, distance from another sign, and other characteristics.

Based on the foregoing, the research of the dependence of the impact of advertising structures on driver distraction and traffic safety aims to open opportunities for a more comprehensive understanding of this issue, especially by traffic infrastructure managers, and also provide incentives to create models [7], procedures and regulations for adequate positioning of advertising structures in accordance with permitted safety requirements.

\section{General Features of the Analyzed Road}

The research presented in this paper was performed on the main city road in the City of Sarajevo, Bosnia and Herzegovina. This road is substantially the central and primary road within the primary network of roads in the City of Sarajevo. This road stretches longitudinally and extends along the entire length of Sarajevo city's center. The carriageway consists of two traffic lanes, each with three lanes intended for the movement of vehicles in both directions. On both sides of the carriageway, for the most part there are pedestrian paths and to a lesser extent, bicycle paths. The permitted vehicle speed along the carriageway is mostly $60 \mathrm{~km} / \mathrm{h}$.

The research covered total of $14.3 \mathrm{~km}$ of the road. For the purpose of more efficient analysis, data collection, calculations, and measurements, the road was segmented into relatively short sections. The intersections of the Main City Road with the transfer routes served for spatial segmentation. Based on this, the Main City Road is segmented into 27 sections that were actually the subject of this research. Figure 1 shows the Main City Road of the City of Sarajevo with the characteristic sections.

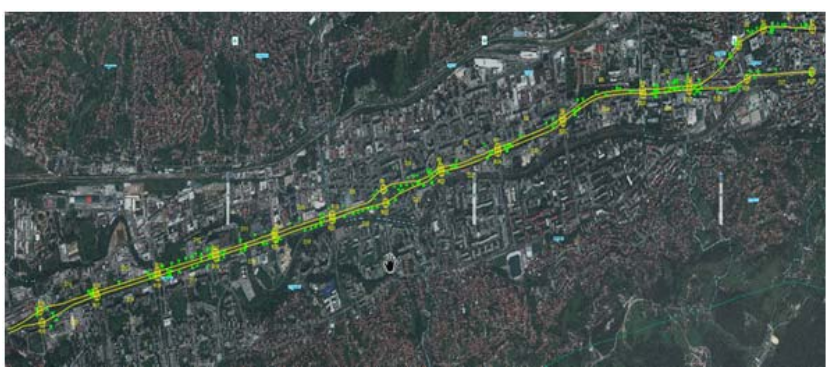

Figure 1. Main Sarajevo City Road

Due to the specifics of the traffic flow conditions and other circumstances, a separate research and analysis was performed for each section and it included three separate segments:

- Calculation of traffic safety indicators along each section;

- Analysis of the impact of the advertising structures' features on traffic safety along each section;

- Research of drivers' gaze and distractions depending on advertising structures along each section.

\section{Research on the Impact of Advertising Structures on Traffic Safety}

\subsection{Analysis of Traffic Safety Indicators Along the Analyzed City Road}

In order to analyze traffic safety along the analyzed city road, the authors collected statistical data on traffic accidents and their consequences in period of three years. Based on the collected data, absolute and relative traffic safety indicators were analyzed. As regards the absolute indicators of traffic safety, traffic accidents were analyzed by specific types (accidents involving fatalities, severely injured persons, slightly injured persons, and material damage). In terms of the above indicators, a type of traffic accident is determined according to the severity of the consequence, regardless of the number of consequences. Also, the absolute indicators of traffic safety were analyzed, which refer to the severity of the consequences of traffic accidents expressed in number of fatalities, severely injured persons, slightly injured persons, and material damage.

Figure 2 shows the distribution of the number of traffic accidents by the analyzed sections; the total number of traffic accidents is shown here, as well as the number of traffic accidents by type. 


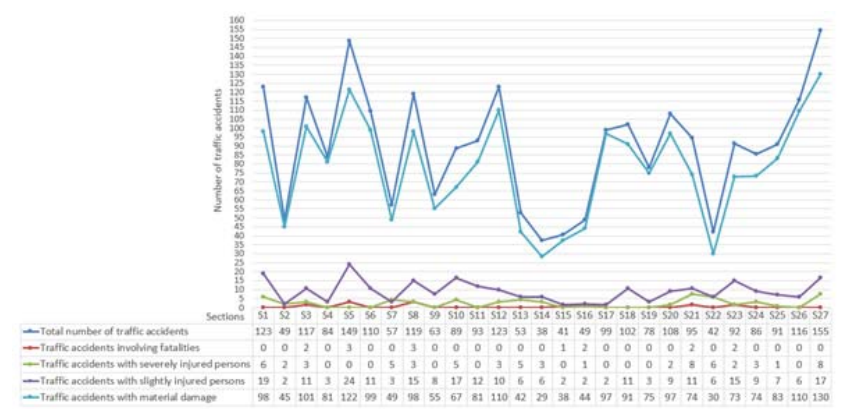

Figure 2. Number of traffic accidents along the analyzed sections by type

Figure 3 shows the distribution of the consequences of traffic accidents by the analyzed sections, including the total number of fatalities, severely injured persons and lightly injured persons is shown.

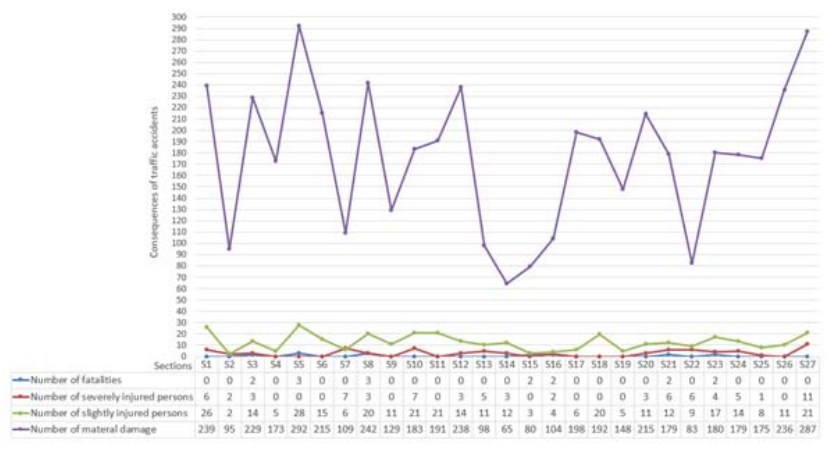

Figure 3. Consequences of traffic accidents along the analyzed sections

In order to provide adequate analysis of the safety situation [8], [9], values of collective and individual risk along the analyzed sections were calculated based on the stated absolute indicators.

Collective risk is commonly used by road managers to better understand how the overall risk to road users is distributed on the road network. Based on the collective risk, high-risk sections are determined and then other methods are used to complete the analysis of high-risk sections (in-depth analysis, case study, conflict technique, etc.). Collective risk of traffic accidents $\left(\mathrm{CR}_{\mathrm{TA}}\right)$ is the average annual number of traffic accidents per kilometer of the observed road section and is calculated using the following equation:

$$
K R_{S N}=\frac{\sum_{i=1}^{G} N_{S N}}{G \cdot L}\left(\frac{\text { traffic accidents }}{k m}\right),
$$

where:

$K R_{S N}$ - collective risk of traffic accidents (number of traffic accidents per kilometer of observed road section),

$N_{S N}$ - number of traffic accidents along the observed section of the road,

$G$ - number of years during which the analysis is preformed, and

$L$ - length of the analyzed section $(\mathrm{km})$.
Figure 4 shows the values of the collective risk of traffic accidents along the analyzed sections

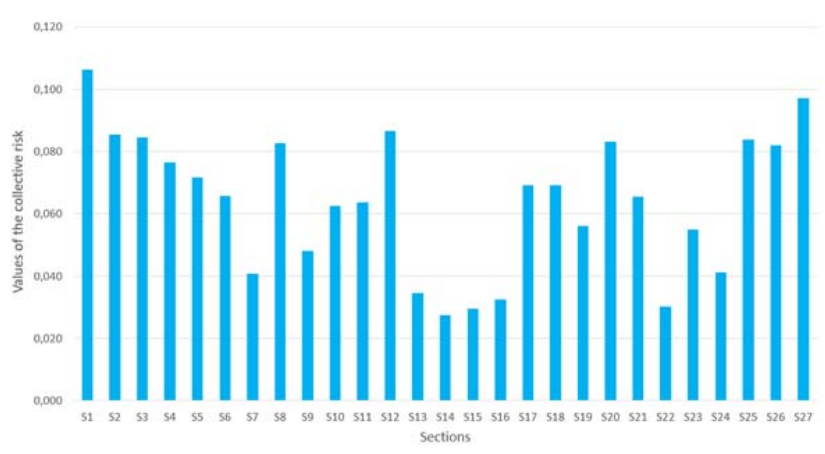

Figure 4. Collective Risk of Traffic Accidents Along the Analyzed Sections

Individual risk indicates the possibility of accidents relevant to exposure. The primary purpose of determining the value of individual risk is to inform traffic participants how their behavior should change in order to minimize the level of risk. Individual risk of traffic accidents $\left(\mathrm{IR}_{\mathrm{TA}}\right)$ is the total number of traffic accidents per million vehicle kilometers along the observed road section and the observed time frame and is calculated using the following equation:

$$
I R_{S N}=\frac{\sum_{i=1}^{G} N_{S N}}{L \cdot 365 \cdot \sum_{i=1}^{G} P G D S_{i}} \cdot 10^{6}\left(\frac{\text { traffic accidents }}{10^{6} \text { vehicles } k m}\right),
$$

where:

$I R_{S N}$ - general individual risk of traffic accidents (weighted value of traffic accidents per million vehicle kilometers of the observed road section),

$P G D S$ - average annual daily traffic along the observed road section (vehicles/day).

Figure 5 shows the values of the individual risk of traffic accidents along the analyzed sections.

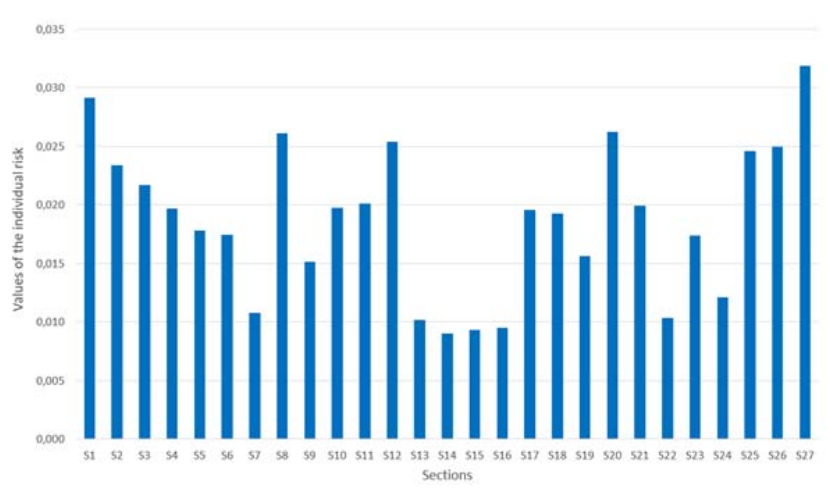

Figure 5. Individual Risk of Traffic Accidents Along the Analyzed Sections

\subsection{Analysis of the Impact of Roadside Advertising Structures' Features on Traffic Along the City Road}

The authors identified characteristics of advertising structures and analyzed them using multi-criteria evaluation in order to determine their impact on 
driver distraction (behavior) which cause risk of conflict situation and/or traffic accidents. The research included all advertising structures located in the immediate proximity of the road, i.e., the traffic zone, which, depending on their position and manner of advertising, can in any way be in the field of view of drivers of motor vehicles moving along the analyzed city road.

Thus, a total of 189 advertising structures were recorded, which, depending on their specific features, were classified into 8 groups, as follows: Billboard, backlight, bus stand advertising, citylight \& premium citylight, cultural posters, LED displays, column, and wallscape.

The impact of advertising structures on traffic safety was analyzed as a potential risk for occurrence or contribution to the occurrence of traffic accidents and conflict situations as it may effectively cause driver distraction detrimental to their driving and traffic situation monitoring. This is particularly important given that the driver's normal response time of about $1.0 \mathrm{~s}$, compared to the time required to notice, read, and understand the advertising content.

In order to analyze the impact of roadside advertising structures on traffic safety, four specific elements, i.e., features of advertising structures were identified as follows: surface area of the advertising structure, distance of the advertising structure from the road, illumination of the advertising structure, and load on driver's field of vision.

The possibility of observation by the driver directly depends on dimensions/surface area of the roadside advertising structures. The larger area of an advertising structure has a greater possibility of distracting drivers, i.e., directing the driver's gaze away from ongoing traffic situation to the content and surface area of the advertising structure. Consequently, in this analysis the smallest surface areas of advertising structures were assigned maximum value of safety impact, while advertising structures with largest surface areas were assigned minimum value. A potential problem with this approach in evaluating surface area of an advertising structure is the fact that textual content on advertising structures with relatively smaller surface areas requires more time to notice, read, and understand.

When evaluating the shorter distance of advertising structures from the road, they were evaluated with maximum values of safety impact, and the values of the impact on safety are reduced if a roadside advertising structure are further away from the road. If an advertising structure is closer to the road, there is a greater possibility of its negative impact on the driver. In addition to the direct impact of proximity, due to its position an advertising structure may indirectly affect traffic safety by reducing the triangles of visibility, especially at intersections. Also, the proximity of advertising structures in open sections of road limits the drivers' field of vision and prevents timely detection of vulnerable traffic participants, including pedestrians and cyclists.
The illumination of advertising structures also has a significant impact on traffic safety and this is especially evident in night driving. In addition to the significant negative impact of illuminated advertising structures, which in nighttime contributes to a greater distraction of the drivers, illumination, depending on features of light used, can blind drivers while driving. Consequently, illumination of advertising structures was evaluated depending on the qualitative and quantitative features of illumination, light source, and intensity and direction of the light beam.

Load on the drivers' field of vision was analyzed depending on the actual position of the advertising structures, as well as relevant to other structures in the immediate proximity of the road. Based on the visibility from the position of the driver's eye trajectory in direction of the advertising structures, and also taking into account the fixed visual obstacles, the calculation of the time of possible visibility of the advertising structures in the driver's field of vision was performed. According to the longer visibility of the advertising structure, an evaluation was performed by assigning them higher values of the impact on traffic safety.

For each advertising structure Topsis method of multi-criteria evaluation of the characteristics of advertising structures was used and individual values of the impact of each analyzed advertising structure on traffic safety were created. The ratio of weighted values of criteria in the procedure of multi-criteria evaluation was: surface area of the advertising structure (0.3), distance of the advertising structure from the road (0.1), illumination of the advertising structure (0.2), and load on driver's field of vision (0.4). After that, depending on the number and positions of advertising structures along individual observed sections, an overall resulting assessment of the impact of all advertising structures on traffic safety of each analyzed section was developed.

Figure 6 shows the values of the influence of the characteristics of advertising structures on traffic safety along the analyzed sections of the city road.

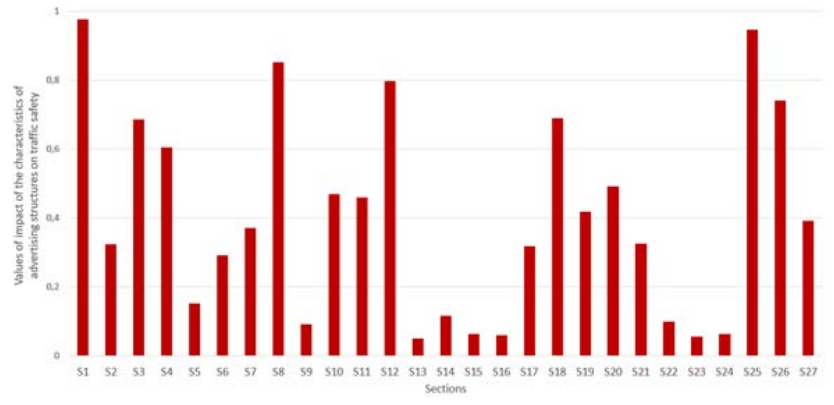

Figure 6. Values of Impact of the Features of Advertising Structures Along the Observed Sections

Based on the final values, it is possible to compare and rank sections and/or intersections according to the highest value of the impact of advertising structures on traffic safety and consequently identify the riskiest sections and/or intersections. 


\subsection{Investigation of Driver Distraction Caused by Advertising Structures Along the Observed City Road}

This study included 25 motor vehicle drivers, with different age and different years of driving experience. In actual day or night traffic conditions each driver drove one ride along the observed city road. The weather conditions during the testing were good, without precipitation, and the road was dry. Visual characteristics of the drivers were tested while driving, specifically the object of fixation of the driver's gaze. Testing of the driver's visual characteristics was performed using Pupil Core device, specialized glasses for recording eyesight and visual characteristics [10]. In their design, weight, and other elements, Pupil Core specialized glasses are almost identical to ordinary glasses for improving eyesight or sunglasses. The device and application Pupil Core belongs to the group of diagnostic devices and applications that use view data as quantitative evidence of human visual processes and attention [11]. Diagnostic devices and applications for eye tracking have significant capabilities and play important role in the processes aimed at preventing risks to traffic hazards caused by distractions in traffic environment [12], [13].

Although drivers included in the research were not told the reasons behind the testing, the use of goggles in some way probably led to more careful behavior and actions while driving. Depending on the subject and goal of the research, the indicator of gaze fixation was used as the most frequently used indicator in similar research and the analysis of visual characteristics of the respondents [6]. Thus, in each test drive, all fixations on structures during the ride that lasted longer than $0.3 \mathrm{~s}$ were recorded, and then only fixations that referred to advertising structures were filtered. Analysis of the impact of and drivers' distraction by advertising structures along the observed city road section was performed on the basis of the number of fixations of drivers' gaze on advertising structures and the spatial distribution of advertising structures.

Figure 7 shows the values of the average number of fixations of the driver's gaze on advertising structures along the observed sections.

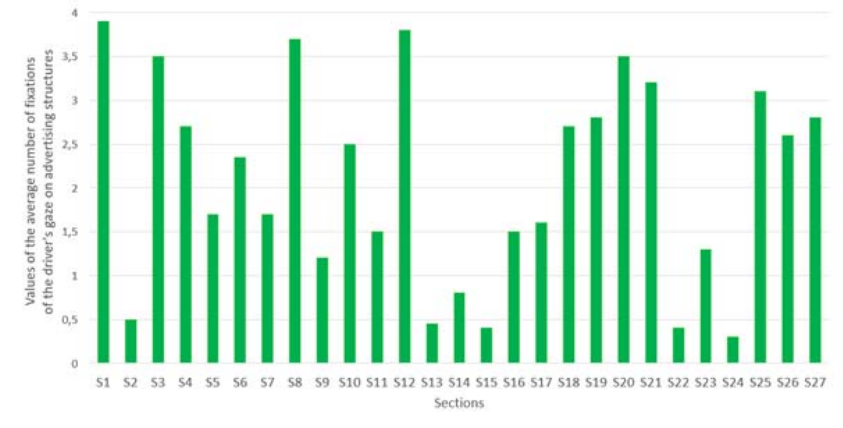

Figure 7. Average values of number of fixations of the driver's gaze on advertising structures along the observed sections

\section{General Features of the Analyzed Road}

A comparative analysis was performed of the stated values for the observed sections of the city road based on the traffic safety indicators described in 3.1, the impact of the characteristics of advertising structures on traffic safety evaluated in 3.2 , and the driver distraction indicators relevant to the advertising structures analyzed and identified in 3.3. Thus, the aim of this research was to determine the correlation between the traffic safety and advertising structures along the observed city road, which altogether relate to advertising and driver distraction.

Given the evident differences in the value ranges of these three groups of indicators, an adequate scaling of values was performed for the purpose of comparative analysis. Figure 8 shows scaled values of the above mentioned three groups of indicators for the observed sections of the road.

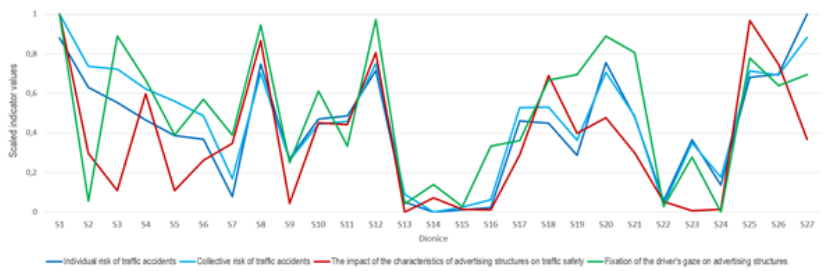

Figure 8. Comparative analysis of the safety indicator values (individual and collective risk of traffic accidents), the impact of the characteristics of advertising structures on traffic safety and fixation of the driver's gaze on advertising structures

Comparing the values in Figure 8, it is evident that only on certain sections and intersections there is a significant dependence between all three groups of characteristic indicators, i.e., that the characteristics of advertising structures only on certain sections and intersections have a significant impact on driver distraction and traffic safety.

In addition, a statistical analysis was performed which include interpretation of data presented in form of graphical and numerical results. The subject of the analysis is focused at determining stochastic relationships between the previously analyzed three groups of parameters, which are related on traffic safety indicators expressed through values individual and collective risk (C), which are considered as dependent variables, with estimated values of impact of advertising structures characteristics (A) and data of recorded values of drivers gaze fixation on advertising structures (B), which are considered as independent variables.

Figures 9, 10, 11, and 12 show scatter diagram of analyzed data which visually provide initial information on the form of dependence between the observed variables and the equation of the linear regression model $y=a+b x$, as well as the values of the coefficient of determination $\mathrm{R}^{2}$. 


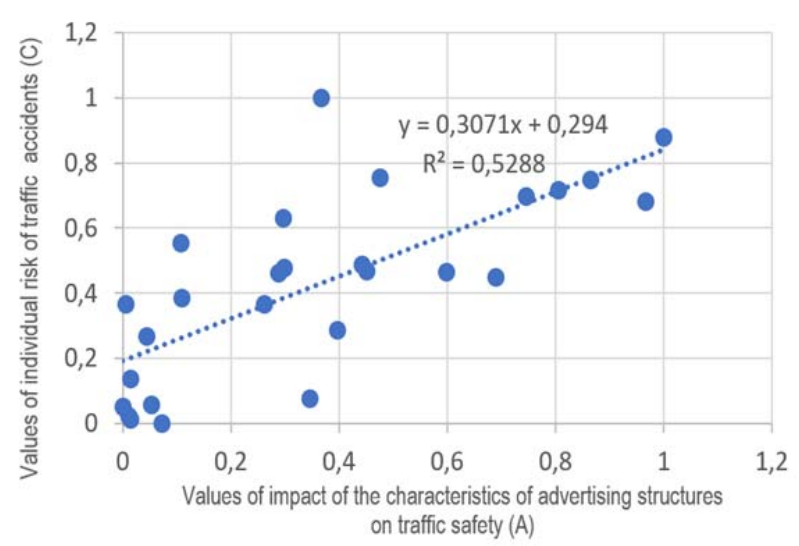

Figure 9. Scatter diagram of data of estimated values of impact of advertising structures' characteristics (A) and values of individual risk of accidents along the observed sections $(C)$, equations of the linear regression model and the coefficient of determination $R^{2}$

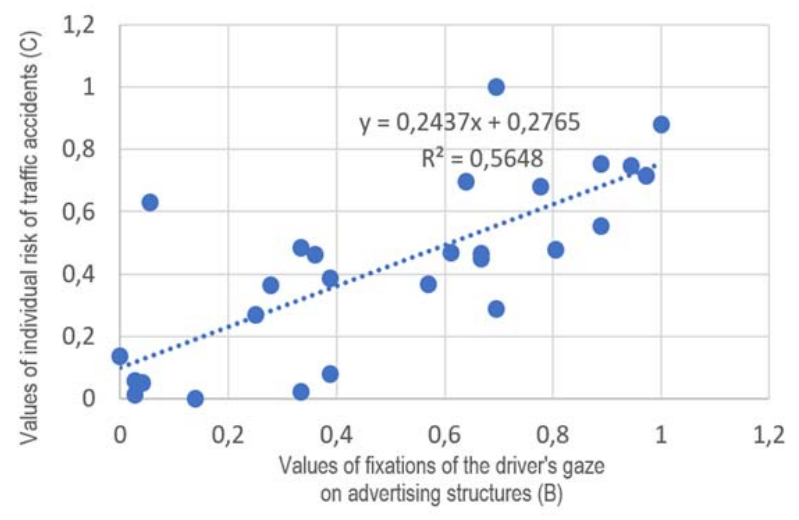

Figure 10. Scatter diagram of data of recorded values of drivers' gaze fixation on advertising structures (B) and values of individual risk of accidents along the observed sections (C), equations of the linear regression model and the coefficient of determination $R^{2}$

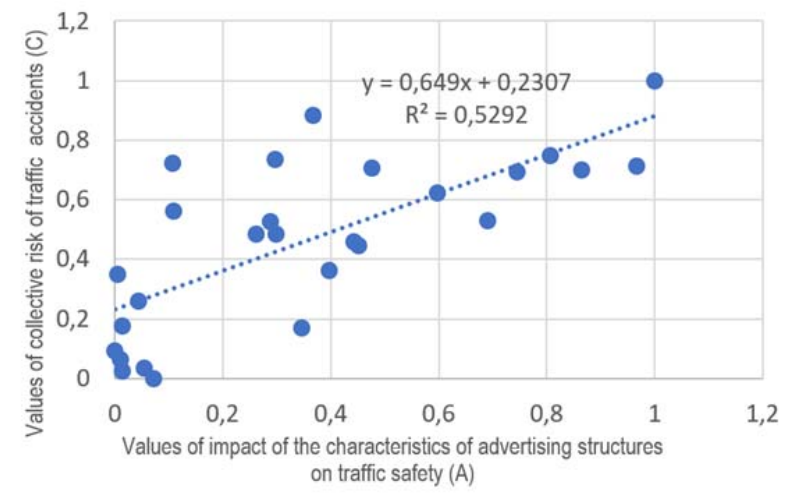

Figure 11. Scatter diagram of data of estimated values of impact of advertising structures' characteristics (A) and values of collective risk of accidents along the observed sections (C), equations of the linear regression model and the coefficient of determination $R^{2}$

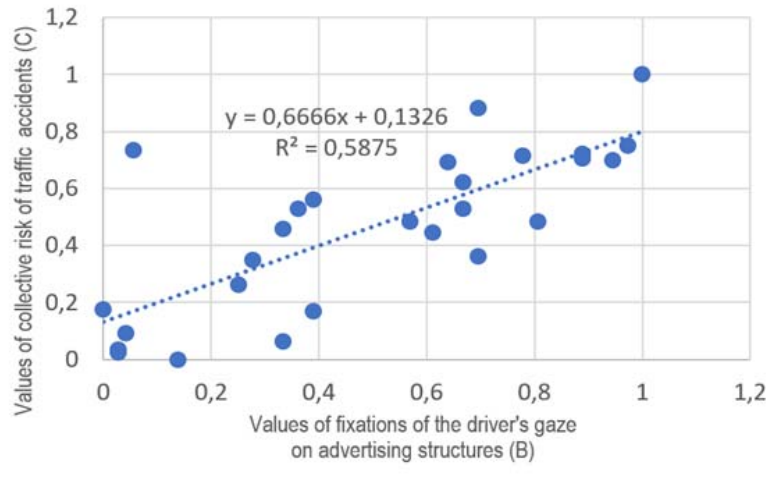

Figure 12. Scatter diagram of data of recorded values of drivers' gaze fixation on advertising structures (B) and values of collective risk of accidents along the observed sections (C), equations of the linear regression model and the coefficient of determination $R^{2}$

The calculated values of the regression coefficients shown in Figures 9, 10, 11 and 12 show that the relationship between the selected dependent and independent variables is direct. The coefficient of determination is interpreted as a measure of representativeness of the regression model, i.e., as the coefficient which can be used to conclude how significant the relationship between the observed variables is as explained by the linear regression model.

Although the values of the obtained coefficient of determination $\mathrm{R}^{2}$ are of medium size, taking into account the relatively limited territorial scope of the survey, as well as the limited number of samples included in the research, it can be concluded that there is a certain relationship between traffic safety and roadside advertising structures erected near the road that are related to advertising and driver distractions.

\section{Conclusion}

Identification and quantification of the causes of traffic accidents are particularly challenging in urban areas, primarily due to the large number of different elements in the immediate proximity of roads. In that regard, one of extremely important elements are advertising structures whose negative impact on traffic safety is manifested through the distraction of drivers, which may ultimately be the cause or contribution of conflict situations and traffic accidents.

Quantifying the connection between the impact of advertising structures on driver distraction and traffic safety aims to open opportunities for a more comprehensive understanding of this issue and the obligation of stakeholders. This primarily concerns the more intensive involvement on the part of competent agencies and legislative bodies in order to create regulations for the adequate placement of 
advertising facilities in accordance with the permitted safety requirements. Expectedly, road infrastructure managers should, within their competencies, also become more involved in intensive treatment of this issue.

By comparing the calculated values of traffic safety indicators, estimated values of the impact of advertising structures on traffic safety, and the values of testing the driver's fixation on advertising structures, it is evident that there is a significant connection between all three groups of characteristic indicators along specific sections of the observed road.

The results of statistical analysis including interpretation of graphical and numerical data representations and the results of regression analysis effectively showed the connection between the influence of advertising structures placed near the road on traffic safety. Although the values of the derived coefficient of determination $\mathrm{R}^{2}$ are of medium size, considering relatively limited territorial scope of the survey and limited number of samples, it can be concluded that there is some correlation between traffic safety and characteristics of roadside advertising structures regarding advertising and driver distractions.

In addition to the impact of roadside advertising structures on the driver's distraction while driving, several other negative impacts have been identified including: occupation of space, visual degradation of space, light pollution, and danger posed by construction of an advertising structures as hazardous obstacles in the immediate proximity of the road.

\section{References}

[1]. Young, K. L., Regan, M. A., \& Hammer, M. (2003). Driver distraction: A review of the literature (report no. 206). Victoria, Australia: Monash University Accident Research Centre.

[2]. Omerhodžić, A., Lindov, O., \& Kosovac, A. (2021, June). Proposal of Conceptual Model for Management Improvement of Dangerous Places on the Road Network. In International Conference "New Technologies, Development and Applications" (pp. 724-736). Springer, Cham. https://doi.org/10.1007/978-3-030-75275-0_80

[3]. Wang, J. S., Knipling, R. R., \& Goodman, M. J. (1996). The role of driver inattention in crashes: new statistics from the 1995 Crashworthiness Data System. In Annual proceedings of the Association for the Advancement of Automotive Medicine (Vol. 40, pp. 377-392). Association for the Advancement of Automotive Medicine.
[4]. Oviedo-Trespalacios, O., Truelove, V., Watson, B., \& Hinton, J. A. (2019). The impact of road advertising signs on driver behaviour and implications for road safety: A critical systematic review. Transportation research part A: policy and practice, 122, 85-98. https://doi.org/10.1016/J.TRA.2019.01.012

[5]. Chattington, M., Reed, N., Basacik, D., Flint, A., \& Parkes, A. (2009). Investigating driver distraction: the effects of video and static advertising. Published project report PPR409. London, England: Transport Research Laboratory.

[6]. Underwood, G., Chapman, P., Brocklehurst, N., Underwood, J., \& Crundall, D. (2003). Visual attention while driving: sequences of eye fixations made by experienced and novice drivers. Ergonomics, 46(6), 629-646.

https://doi.org/10.1080/0014013031000090116

[7]. Vrkljan, J., Mustapić, M., \& Burazer Pavešković, J. (2021). Roadside ad space selection model from the aspect of road safety. Safety, 63.

[8]. Yakimov, M. (2020). Methods for assessing road traffic accident risks with changes in transport demand structure in cities. Transportation research procedia, 50, 727-734.

[9]. Chand, A., Jayesh, S., \& Bhasi, A. B. (2021). Road traffic accidents: An overview of data sources, analysis techniques and contributing factors. Materials Today: Proceedings.

[10]. Kassner, M., Patera, W., \& Bulling, A. (2014, September). Pupil: an open source platform for pervasive eye tracking and mobile gaze-based interaction. In Proceedings of the 2014 ACM international joint conference on pervasive and ubiquitous computing: Adjunct publication (pp. 11511160). https://doi.org/10.1145/2638728.2641695

[11]. Duchowski, A. T. (2002). A breadth-first survey of eye-tracking applications. Behavior Research Methods, Instruments, \& Computers, 34(4), 455-470. https://doi.org/10.3758/BF03195475

[12]. Driver Monitoring System.(2020). Eye Tracking Technology. Smart Eye. (n.d.). Retrieved from: https://smarteye.se/automotive-solutions/ [accessed: 27 September 2021].

[13]. Lindov, O., \& Omerhodžić, A. (2020, June). New Technologies for Improving Driver Response Efficiency in Risk Prevention from Traffic Environment. In International Conference "New Technologies, Development and Applications" (pp. 570-580). Springer, Cham. https://doi.org/10.1007/978-3-030-46817-0_67 